\title{
A novel 1,2,3-benzotriazolium based ionic liquid monomer for preparation of MMT/poly ionic liquid (PIL) pH-sensitive positive charge nanocomposites
}

\author{
FATEMEH SOGHRA JAHED ${ }^{\mathrm{a}}$, MOHAMMAD GALEHASSADI ${ }^{\mathrm{a}, *}$ and \\ SOODABEH DAVARAN ${ }^{\mathrm{b}}$ \\ ${ }^{a}$ Department of Chemistry, Faculty of Science, Azarbaijan Shahid Madani University, Tabriz, Iran \\ ${ }^{b}$ Biotechnology Research Center, Tabriz University of Medical Sciences, Tabriz, Iran \\ E-mail: mg-assadi@azaruniv.ac.ir
}

MS received 6 October 2018; revised 22 December 2018; accepted 2 January 2019; published online 13 February 2019

\begin{abstract}
In this work, a new ionic liquid (IL) with two acidic and vinylic functional groups based on 1,2,3benzotriazolium cation was synthesized. This IL monomer was intercalated into the montmorillonite (MMT) layers by the ion exchange reaction and subsequently copolymerized with the IL monomer and methacrylic acid in order to obtain positive charge $\mathrm{pH}$-sensitive nanocomposites. The structure of the IL monomer was characterized by FT-IR and ${ }^{1} \mathrm{H}-\mathrm{NMR}$ spectroscopy, and the structure of the nanocomposites was studied and confirmed by the FT-IR, XRD, TGA, SEM, and EDX data. These pH-sensitive nanocarriers were used to load and in vitro release of the anticancer drug, methotrexate (MTX) in $\mathrm{pH}=4$ and $\mathrm{pH}=7.4$. The results showed that the release is $\mathrm{pH}$ dependent and more effective in acidic $\mathrm{pH}$; therefore, these nanocarriers have potential to be used for cancer therapy.
\end{abstract}

Keywords. IL monomer; montmorillonite; nanocomposites; nanocarriers; methotrexate; cancer therapy.

\section{Introduction}

Drug delivery or feedback regulated release systems are smart materials that carry active substances to the target site in a given time and concentration, by adjusting the release rate to the level of a biomarker. ${ }^{1}$ Sensitiveness to biomarker signals is achieved by means of synthetic materials such as functional polymers. Polymers have unique properties that make them appropriate for drug delivery applications. Based on their chemical structure, functional polymers can be divided into three categories: $\mathrm{pH}$-sensitive, biocompatible, and cationic polymers. ${ }^{2}$ The $\mathrm{pH}$ gradient is one of the first stimuli in the body that attracted considerable attention, and it has been predominantly studied in recent biomedical researches. The $\mathrm{pH}$-sensitive polymers deliver drugs into cells by the environmental $\mathrm{pH}$ changes. ${ }^{3}$ A large number of drug delivery systems (DDSs) containing polymers, such as hydrogels, ${ }^{4,5}$ liposome, ${ }^{6,7}$ and MMT/polymer nanocomposites $^{8,9}$ have been studied during recent years.
Nowadays, cancer is a common fatal disease. Due to the side effects of chemotherapy drugs on healthy cells, their use in the treatment of cancer produces major problems. ${ }^{10}$ Targeted drug release has fewer side effects, as this technique is supposed to reach a more accurate target. Nanoparticles are one of the most important materials that are used in the anti-cancer DDSs. ${ }^{11}$ Nanoparticles have unique physicochemical and biological properties due to their small size. For instance, they can easily cross the cellular barriers due to their enhanced reactive area, ${ }^{12}$ and therefore, are suitable for use as anti-cancer drug carriers. MMT is one of the naturally nano-sized swelling clay minerals which has a large specific surface area; it exhibits good adsorbing ability, cation exchange capacity, standout adhesive ability, and drug-carrying capability. MMT is a common ingredient like both the filler and active agents in the pharmaceutical products. ${ }^{13}$ Ghanshyam V. Joshi et al., studied the timolol maleate (TM) controlled release from the MMTTM hybrid. ${ }^{14}$ Ruxandra Irina Iliescu et al., prepared and

\footnotetext{
*For correspondence

Electronic supplementary material: The online version of this article (https://doi.org/10.1007/s12039-019-1592-y) contains supplementary material, which is available to authorized users.
} 
characterized some MMT/antitumor drug hybrids which can be used for oral chemotherapy. ${ }^{15}$

Considering the importance of drug delivery, the design of new advanced functional materials for drug delivery targets is an important task in pharmacotherapy. Ionic liquids (ILs) are known as the salts with low melting points typically below $100^{\circ} \mathrm{C}$. Recently, many studies have been done on the use of ILs in the pharmaceutical industry, including (1) as prodrug ILs, ${ }^{16}(2)$ as a solvent for synthesis and purification of pharmaceutical compounds ${ }^{17,18}$ and for dissolving poorly soluble drug molecules, ${ }^{19}$ and (3) DDSs. ${ }^{8,20}$ ILs are extensively used in the modification of clay nanoparticles for preparation of organic-inorganic polymer nanocomposites, which have both inorganic and organic ingredient properties in a single material. ${ }^{21}$ In most of the researches, IL monomers were intercalated into MMT. Afterwards, they copolymerized with other suitable monomers such as the methacrylic acid to obtain $\mathrm{pH}$ sensitive nanocomposites. ${ }^{22,23}$

The aim of this study is to synthesize and characterize a novel 1,2,3-benzotriazolium based dual acidic and vinylic functional IL and using it to prepare an $\mathrm{MMT} /$ poly ionic liquid (PIL) $\mathrm{pH}$-sensitive positive charge nanocomposite without any need for the other monomers. Having an acidic group and a positive charge, this nanocomposite is favorable for the release of negatively charged drugs.

\section{Experimental}

\subsection{Materials}

4-vinylbenzyl chloride (VBC), 2,6-di-tert-butyl-4-methyl phenol (BHT), methotrexate (MTX), sodium, and $\mathrm{HCl} 37 \%$, were purchased from Aldrich (America). Benzotriazole (Bt), triethylamine (TEA), $\alpha, \alpha^{\prime}$-azobis(isobutyronitrile) (AIBN), dimethylformamide (DMF), tetrahydrofuran (THF), acetonitrile, diethyl ether, hexane, ethylacetate, methacrylic acid, chloroacetic acid, sodium dihydrogen phosphate, potassium hydrogen phosphate, sodium sulfate, and silica gel $(60(0.04-$ $0.063 \mathrm{~mm})$ ), were purchased from Merck (Germany). Montmorillonite was purchased from Kunimine industries Co. (Japan).

\subsection{Characterization techniques}

Infrared spectra were recorded with a 4600 Unicam FT-IR spectrophotometer. ${ }^{1} \mathrm{H}$ (400 MHz) NMR (nuclear magnetic resonance) spectrum was recorded in dimethyl sulfoxide- $\mathrm{d}_{6}$ (DMSO- $\mathrm{d}_{6}$ ) on a Bruker $400 \mathrm{MHz}$ spectrometer at room temperature. A TA instrument (Mettler Toledo 851e, Germany) was used to record the thermogravimetric analysis
(TGA) data, under $\mathrm{N}_{2}$ from $50^{\circ} \mathrm{C}$ to $850^{\circ} \mathrm{C}$ at the $10^{\circ} \mathrm{C} / \mathrm{min}$ heating ramp. Differential scanning calorimetry (DSC) was performed with a TA instrument (Perkin-Elmer) at the heating rate of $10^{\circ} \mathrm{C} / \mathrm{min}$ in the air. X-ray diffraction (XRD) analysis was carried out by a Bruker AXS model D8 advanced diffractometer. A Philips PU 8620 ultraviolet spectrophotometer was used to determine the amount of drug released. The FESEM images were registered using the image analysis software produced by TSCAN Co. (Czech), in University of Kurdistan, and the energy-dispersive X-ray spectroscopy (EDX) data were recorded using a scanning electron microscope (SEM) device produced by phenom Co., the Netherlands model prox, in Azarbaijan Shahid Madani University.

\subsection{Experimental procedure}

2.3a Synthesis of 1-carboxymethyl-1,2,3-benzotriazole (CmBt): 1-H-1,2,3-benzotriazole $(1 \mathrm{~g}, 8.34 \mathrm{mmol})$ was added to a $100 \mathrm{~mL}$ flask containing $25 \mathrm{~mL}$ dry THF as a solvent. Then, TEA $(2.34 \mathrm{~mL}, 8.34 \mathrm{mmol})$ was added to it and the mixture was stirred at room temperature. After 2 $\mathrm{h}$, chloroacetic acid $(0.8 \mathrm{~g}, 8.5 \mathrm{mmol})$ dissolved in $10 \mathrm{~mL}$ of dry THF was added to the mixture dropwise, during $20 \mathrm{~min}$. The reaction mixture was stirred for $24 \mathrm{~h}$ at room temperature. The product was purified using column chromatography (hexane/ethylacetate, 1:1). The melting point of this compound is $50^{\circ} \mathrm{C}$.

\section{3b Synthesis of ionic liquid monomers (ILMs):}

CmBt (10 mmol), 4-vinylbenzyl chloride (11 mmol), and inhibitor 2,6-di-tert-butyl-4-methyl phenol $(0.1 \mathrm{mmol})$ were added to a $50 \mathrm{~mL}$ two-necked round bottom flask equipped with a magnetic stirrer. This mixture was stirred under $\mathrm{N}_{2}$ atmosphere at $55-60{ }^{\circ} \mathrm{C}$ for $48 \mathrm{~h}$. Then the product was washed several times by excess dry ethyl acetate to leave unreacted materials. The obtained pure product (ILM-1, Scheme 1) was dried under vacuum. The melting point of ILM- 1 is $118^{\circ} \mathrm{C}$. Then the ILM-1 $(2.43 \mathrm{mmol})$ was dissolved in deionized water $(40 \mathrm{~mL})$ and $\mathrm{NaPF}_{6}$ salt dissolved in deionized water was added to it drop by drop. The mixture was stirred at room temperature. After $24 \mathrm{~h}$, the obtained precipitate was collected and washed several times with deionized water to remove the unreacted materials and a chloride anion. Silver nitrate testing indicated that no chloride ion exists, hence the product (ILM-2, Scheme 1) was dried over $\mathrm{CaCl}_{2}$ under vacuum. The melting point of this monomer is $99^{\circ} \mathrm{C}$.

2.3c Intercalation of ionic liquid monomer in MMT (OMMT): Na-MMT $(0.5 \mathrm{~g})$ was dispersed in $\mathrm{H}_{2} \mathrm{O} / \mathrm{EtOH}$ $(3: 1,30 \mathrm{~mL})$ by ultra-sonication for $15 \mathrm{~min}$ and was stirred at $60^{\circ} \mathrm{C}$ for $2 \mathrm{~h}$. Then the reaction temperature was reached $50^{\circ} \mathrm{C}$. Afterwards, ILM-1 $(1 \mathrm{~g})$ solubilized in $\mathrm{H}_{2} \mathrm{O} / \mathrm{EtOH}$ $(1: 1,10 \mathrm{~mL})$ was added dropwise into the mixture in $30 \mathrm{~min}$. Then this suspension was vigorously stirred for $48 \mathrm{~h}$. The resultant precipitate was filtered and washed several times with distilled water until no chloride ion was detected by silver nitrate testing. The product was dried under vacuum for $24 \mathrm{~h}$. 


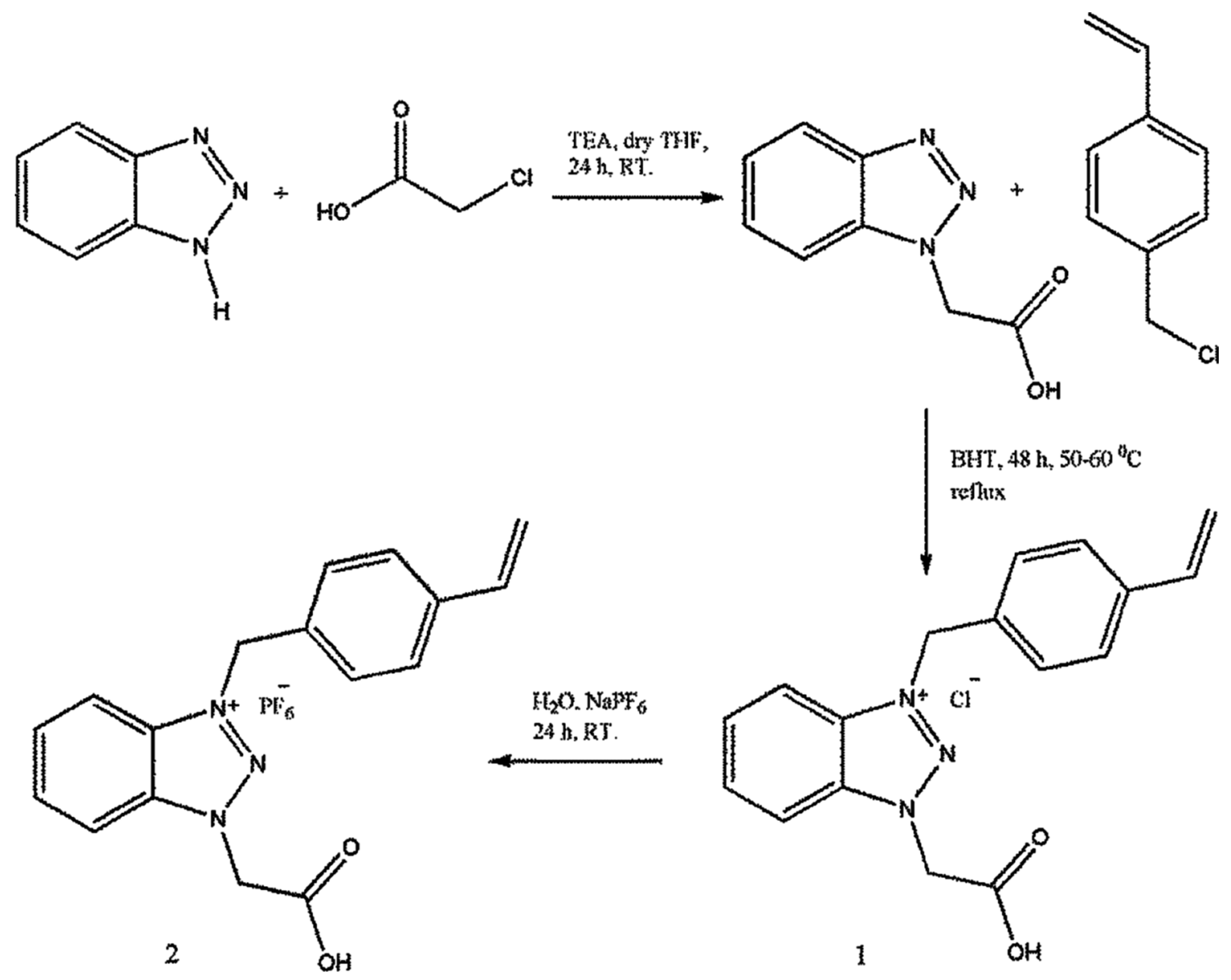

Scheme 1. Synthesis of dual functional ILM.

2.3d Preparation of the OMMT-PIL nanocomposite:

This nanocomposite was prepared by polymerization of the suspension of ILM-2 (0.2 g) and OMMT (0.2 g), in acetonitrile as a solvent in the presence of AIBN ( $2 \mathrm{~mol} \%)$, as an initiator at $70^{\circ} \mathrm{C}$ for $48 \mathrm{~h}$ under argon atmosphere. The resultant product was centrifuged and washed by dry acetonitrile $(3 \times 10 \mathrm{~mL})$ and was dried under vacuum.

\section{$2.3 \mathrm{e}$ Preparation of the OMMT-CO(PIL-MAA)} nanocomposite: This nanocomposite was prepared by copolymerization of the suspension of ILM-2 $(0.1 \mathrm{~g})$, MAA monomer $(0.1 \mathrm{~g})$ and OMMT $(0.2 \mathrm{~g})(0.5: 0.5: 1, \mathrm{~g} / \mathrm{g} / \mathrm{g})$ in acetonitrile as a solvent in the presence of AIBN ( $2 \mathrm{~mol} \%)$, as an initiator at $70^{\circ} \mathrm{C}$ for $48 \mathrm{~h}$ under argon atmosphere. The resultant product was centrifuged and washed by dry acetonitrile $(3 \times 10 \mathrm{~mL})$ and was dried under vacuum.

2.3f Drug loading and in vitro release study: In a solution $(5 \mathrm{~mL})$ containing MTX $(10 \mathrm{mg}), 100 \mathrm{mg}$ of each nanocomposite was dispersed by using an ultrasonic generator device for $10 \mathrm{~min}$. Then, the mixture was stirred at room temperature for $24 \mathrm{~h}$. The MTX loaded nanocomposites were centrifuged at $12000 \mathrm{rpm}$ for $10 \mathrm{~min}$ to remove unloaded MTX and was dried at room temperature under vacuum. The supernatants were kept for measurement of drug concentration which was done by a standard MTX concentration curve.
Each obtained pH-responsive MTX-loaded nanocomposite was dispersed in $3 \mathrm{~mL}$ buffer solutions namely simulated gastric fluid and simulated intestinal fluid (SGF, $\mathrm{SIF}$ ) for $5 \mathrm{~min}$ and was placed in a separate dialysis bag. Then the bags were located in $10 \mathrm{~mL}$ of release media at $37^{\circ} \mathrm{C}$. During the release study, the medium was slowly stirred. At appropriate times, $3 \mathrm{~mL}$ of each solution was collected and $3 \mathrm{~mL}$ of the same fresh buffer was added to the release profile. The amount of released MTX was measured by a UV-vis spectrophotometer at $300 \mathrm{~nm}$. The content of the encapsulated and released drug was estimated with the following formulas, respectively:

Drug entrapment content (\%)

$$
=\frac{\text { Mass of drug in nanocomposite }}{\text { Initial mass of drug }} \times 100
$$

Drug released content $(\%)$

$$
=\frac{\text { Total amount of drug in release medium }}{\text { The amount of drug in nanocomposite }} \times 100
$$

\section{Results and Discussion}

\subsection{Characterization}

3.1a IL monomer characterization: The synthesis of the dual functional ILM is shown in Scheme 1. The 


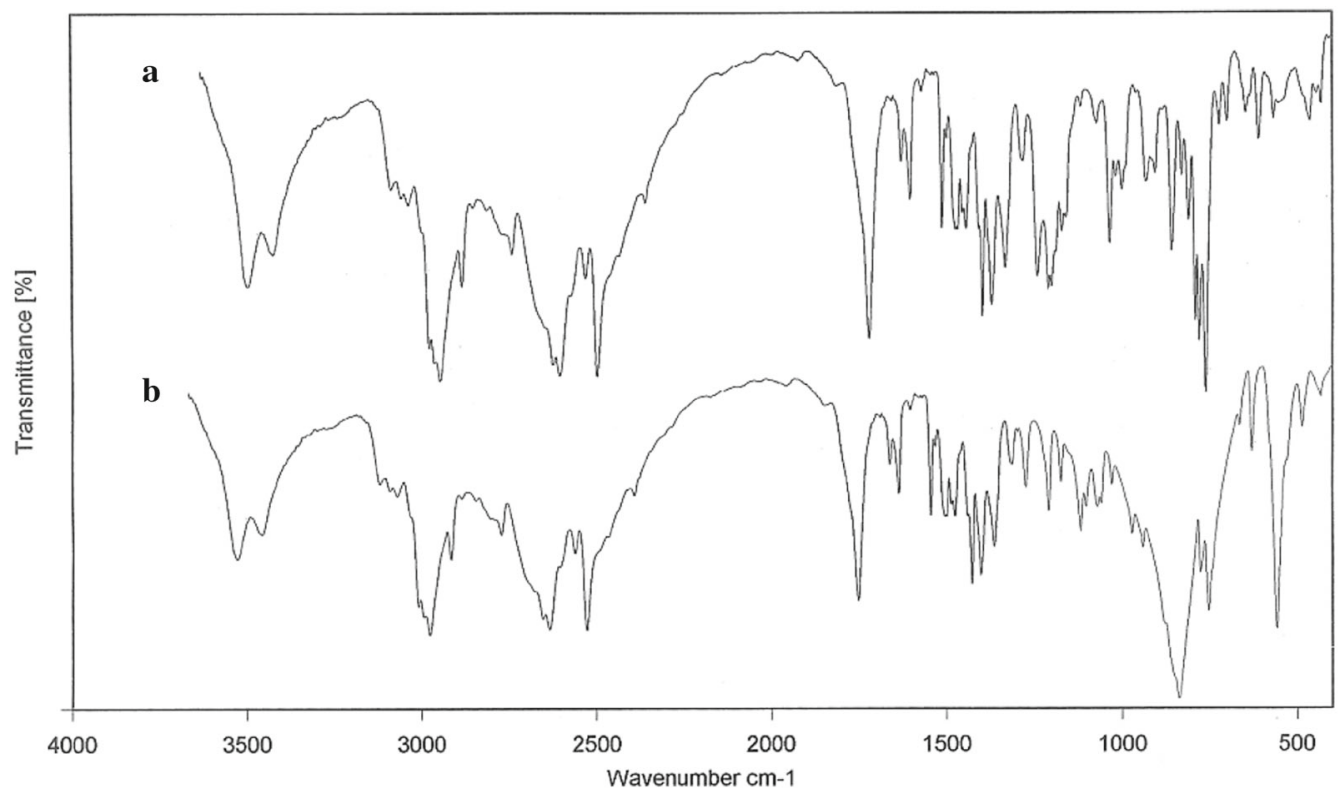

Figure 1. The FT-IR spectra of ILM-1 (a) and ILM-2 (b).

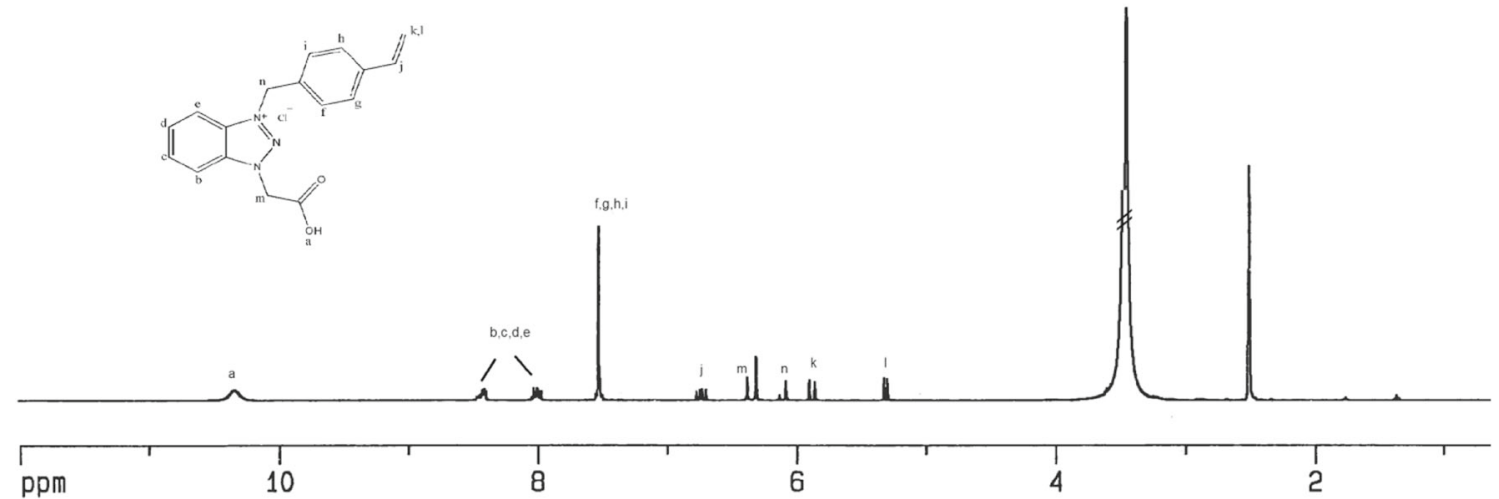

Figure 2. $\quad{ }^{1} \mathrm{H}$ NMR spectrum of ILM-1.

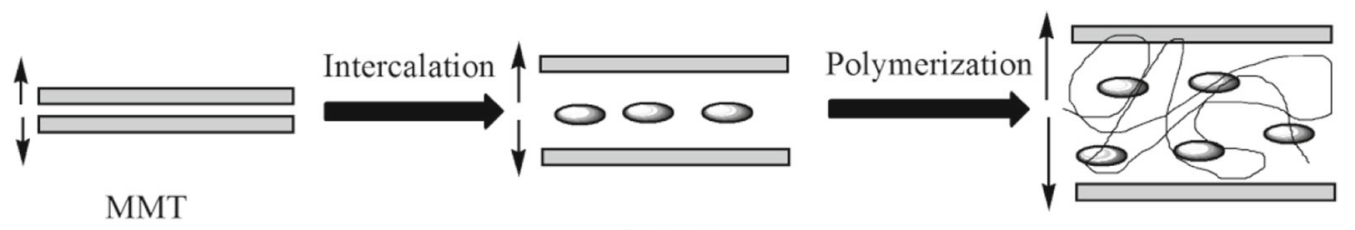

OMMT

Nanocomposite

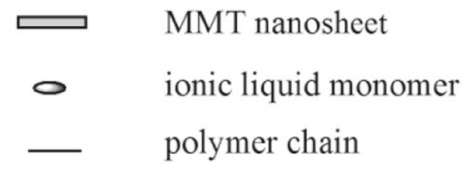

Figure 3. Synthesis route of nanocomposites.

chemical structure of ILM was characterized by FT-IR, ${ }^{1}$ HNMR. Figure 1 and Figure 2 show the ${ }^{1} \mathrm{H}$ NMR and FT-IR spectra, respectively.
FT-IR (neat, $\mathrm{KBr}$ ): ILM-1: Figure 1A, represent the characteristic peaks of this monomer: $3497 \mathrm{~cm}^{-1}(\mathrm{OH}$, acid), $3000 \mathrm{~cm}^{-1}$ (C-H, aromatic), 2884, $2946 \mathrm{~cm}^{-1}$ 


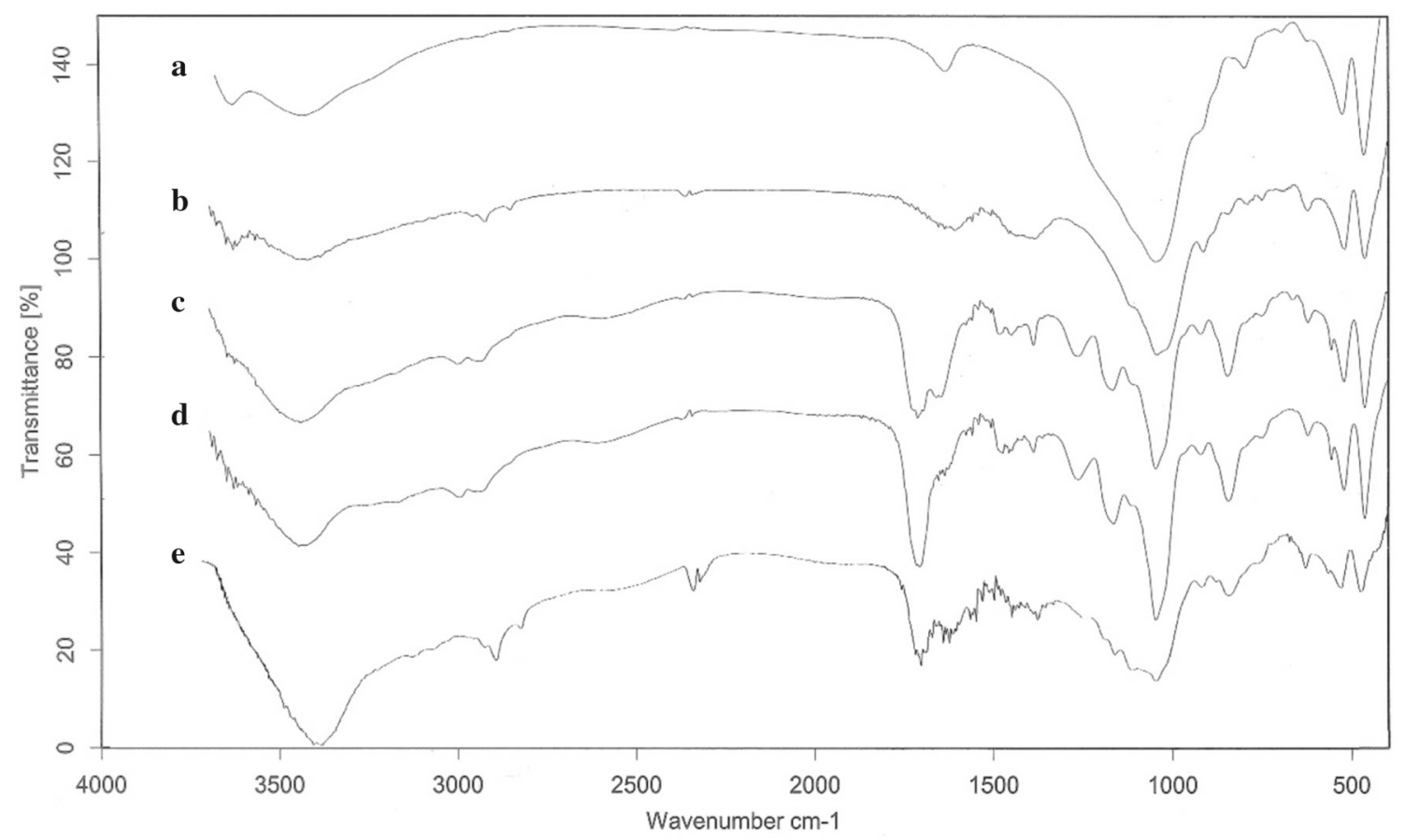

Figure 4. FT-IR spectra of (a) $\mathrm{Na}^{+}-\mathrm{MMT}$, (b) OMMT, (c) OMMT-PIL, (d) OMMT-CO(PIL-MAA), (e) OMMT-PIL, (f) MTX\&OMMT-PIL.

(C-H, aliphatic), $1720 \mathrm{~cm}^{-1}(\mathrm{C}=\mathrm{O}$, acid $), 1604 \mathrm{~cm}^{-1}$ $(\mathrm{C}=\mathrm{C}$, vinyl $), \quad 1408-1513 \mathrm{~cm}^{-1} \quad(\mathrm{C}=\mathrm{C}$, aromatic $)$, $1445 \mathrm{~cm}^{-1}$ (triazole).

ILM-2: in the FT-IR spectrum of this monomer (Figure $1 \mathrm{~B}$ ), in addition to other peaks, the P-F peak at $859 \mathrm{~cm}^{-1}$ confirms the anion exchange reaction.

${ }^{1} \mathrm{H}$ NMR (400 MHz, DMSO-d $\left.\mathrm{d}_{6}, \mathrm{ppm}\right): 10.32(1 \mathrm{H}, \mathrm{s}$, $-\mathrm{COOH}), 8.41(2 \mathrm{H}, \mathrm{m}, \mathrm{Bt}), 7.99(2 \mathrm{H}, \mathrm{m}, \mathrm{Bt}), 7.52(4 \mathrm{H}$, $\mathrm{m}$, styrene), $6.73\left(1 \mathrm{H}, \mathrm{dd},-\mathrm{CH}=\mathrm{CH}_{2}\right.$, vinyl $), 6.30(2 \mathrm{H}$, s, N- $\left.\underline{\mathrm{CH}}_{2}-\mathrm{COOH}\right), 6.0\left(2 \mathrm{H}, \mathrm{s}, \mathrm{N}-\mathrm{CH}_{2}-\mathrm{ph}\right), 5.8,5.3$ $\left(1 \mathrm{H}, 1 \mathrm{H}, \mathrm{d}, \mathrm{d},-\mathrm{CH}=\underline{\mathrm{CH}}_{2}\right.$, vinyl).

3.1b Nanocomposite characterization: The ILM-1 was used to modify MMT that was named as OMMT. The OMMT-PIL nanocomposite was prepared by polymerization of ILM-2, and the OMMT-CO(PIL-MAA) nanocomposite was prepared by copolymerization of ILM-2 and MAA in the presence of OMMT (Figure 3). The chemical structure of the OMMT, OMMT-PIL, and OMMT-CO(PIL-MAA) nanocomposites were characterized by FT-IR, XRD, SEM, EDS, and TGA analyses.

\subsubsection{FT-IR}

Chemical structure of OMMT and nanocomposites were studied by the FT-IR spectroscopy. It can be seen in Figure 4 in all spectra, absorption bands at $524 \mathrm{~cm}^{-1}$, $917 \mathrm{~cm}^{-1}$, and $1044 \mathrm{~cm}^{-1}$ are related to bending vibration of Si-O-Al and stretching vibration of Al-Al-OH and $\mathrm{Si}-\mathrm{O}-\mathrm{Si}$, respectively. The stretching vibration of

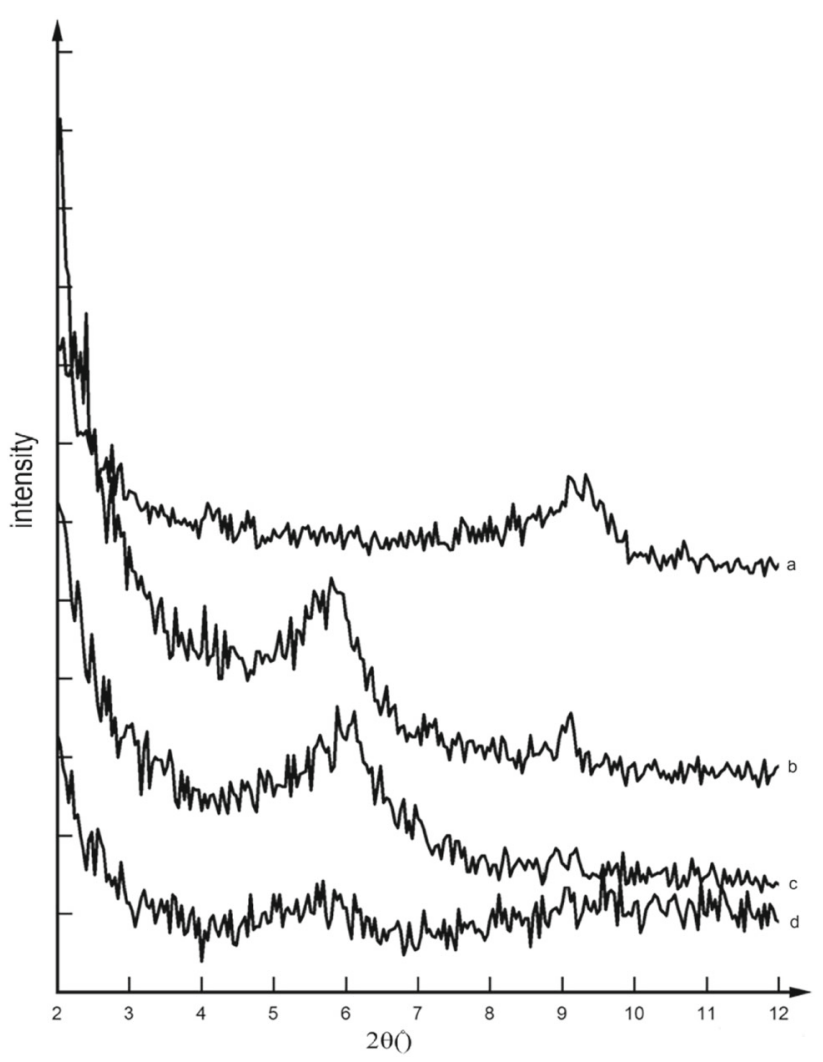

Figure 5. The XRD patterns of: (a) MMT, (b) OMMT (c) OMMT-CO(PIL-MAA) and (d) OMMT-PIL.

the structural hydroxyl group in the MMT and interlayer water was observed at $3690 \mathrm{~cm}^{-1}$ and $3454 \mathrm{~cm}^{-1}$, respectively. In the spectra of Figure $4 \mathrm{~b}$, adsorption 

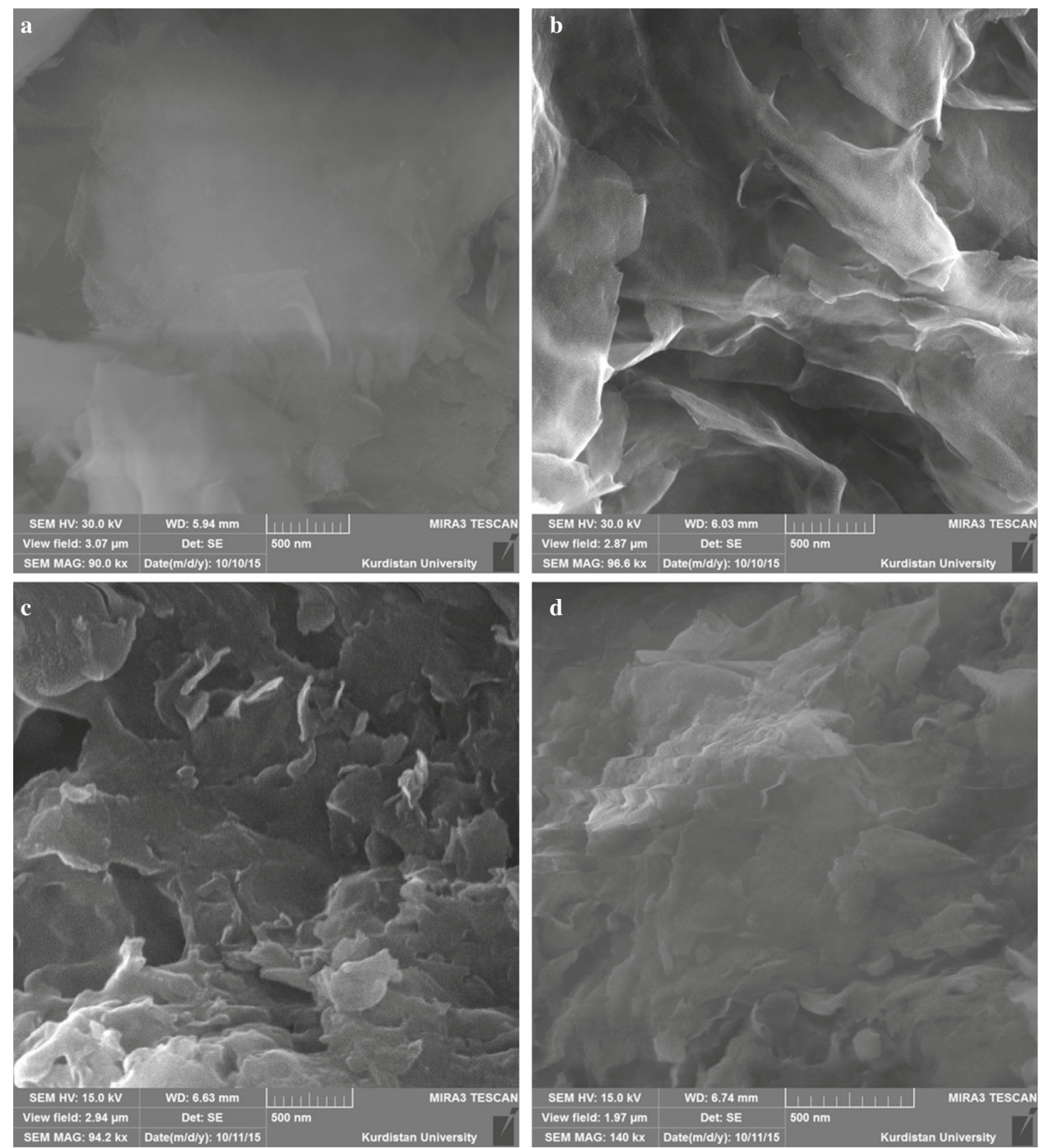

Figure 6. The SEM images of: (a) pristine MMT; (b) IL modified MMT (OMMT); (c) OMMT-PIL nanocomposite; (d) OMMT-CO(PIL-MAA) nanocomposite.

bonds at $1210 \mathrm{~cm}^{-1}, 1450 \mathrm{~cm}^{-1}, 1609 \mathrm{~cm}^{-1}, 1721 \mathrm{~cm}^{-1}$, $2923 \mathrm{~cm}^{-1}$, and $3000 \mathrm{~cm}^{-1}$ were attributed to $\mathrm{C}-\mathrm{O}$ of the acid, triazole, $\mathrm{C}=\mathrm{C}$ aromatic, $\mathrm{C}=\mathrm{O}$ of the acid, $\mathrm{C}-$ $\mathrm{H}$ aliphatic, and $\mathrm{C}-\mathrm{H}$ aromatic, which confirmed that organic cation of IL is replaced with sodium cation in the interlayer of MMT. In the spectra of Figure $4 \mathrm{c}$ and Figure $4 d$, the absorption bond of $\mathrm{C}=\mathrm{O}$ acidic functional group at $1721 \mathrm{~cm}^{-1}$ has been stronger as well as all of the other peaks, due to polymerization of ILM-2 in the interlayer and surface of MMT, and FT-IR device can easily identify the functional groups easily. In the spectra of Figure $4 d$, the intensity of the $C=C$ aromatic peak decreased, because of the low percentage of the PIL in the OMMT-CO(PIL-MAA) nanocomposite toward OMMT-PIL.

The FT-IR spectra in Figure 4e reveal the new absorption peaks in $1640 \mathrm{~cm}^{-1}$ and $1520 \mathrm{~cm}^{-1}$ which refer to the stretching vibration of the $\mathrm{CO}-\mathrm{NH}$ bond and the bending vibration of the $-\mathrm{NH}_{2}$ group of MTX, respectively. On the other hand, a decrease in peak intensity at $1721 \mathrm{~cm}^{-1}$ and $1044 \mathrm{~cm}^{-1}$ is due to the ionic interaction between the drug and carrier. Therefore, FT-IR results confirm the successful MTX loading on the carrier. 

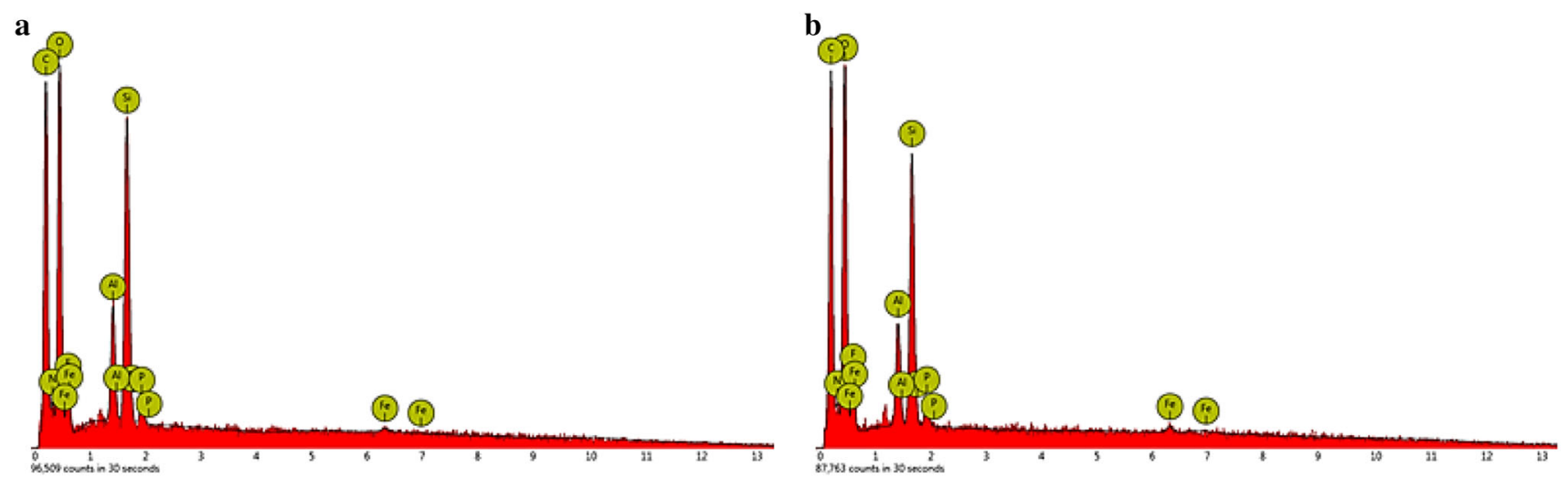

Figure 7. EDS analysis for (a) OMMT-PIL nanpcomposite; (b) OMMT-CO(PIL-MAA).

\subsubsection{XRD}

Structural changes of the MMT nanoparticles in the cation exchange reaction and preparation of organicinorganic nanocomposites are determined by variation in the XRD pattern. The XRD pattern of MMT, OMMT, and nanocomposites are shown in Figure 5, the Bragg between $2 \theta=2^{\circ}-12^{\circ}$ was recorded. As seen in Figure $5 \mathrm{a}$, MMT has a peak in $2 \theta=9.3^{\circ}$ which shifted to $2 \theta=6^{\circ}$ after modification with ILM-1 (Figure 5b). According to Bragg's law, the displacement of the peak replaces to a lower reflection angle, is due to the increase of d-spacing of MMT, which confirm the cation exchange reaction is carried out and sodium cations have been replaced with ILM-1 cations. The d-spacing was increased from $9.45 \mathrm{~nm}$ in MMT to $14.81 \mathrm{~nm}$ in OMMT. The d-spacing of the OMMT-CO(PIL-MAA) (d-spacing is $15.5 \mathrm{~nm}$ ) (Figure 5c) nanocomposite was not very different from that of OMMT (d-spacing is $14.81 \mathrm{~nm})$. It can be concluded that the polymerization occurred out of the MMT layers. But the d-spacing of OMMT-PIL (16.85 nm) (Figure 5d) is higher than that of OMMT and it can be said that the polymerization occurred in and outside the MMT layers.

\subsubsection{SEM and EDS}

The SEM photographs were used to determine the surface morphology of the MMT, OMMT and OMMT-PIL nanocomposites. The images (Figure 6) clearly show the layered structure of MMT. In the OMMT image (Figure 6b), the changing in morphology is quite evident. The image Figure 6c, confirms that the layers of MMT were filled with polymer and the structure became more homogenous.

The presence of N, C, P, and F atoms in the nanocomposite structures was confirmed by the EDS studies (Figure 7), which confirm the formation of nanocomposites. In the EDS spectrum of OMMT-CO(PIL-MAA)

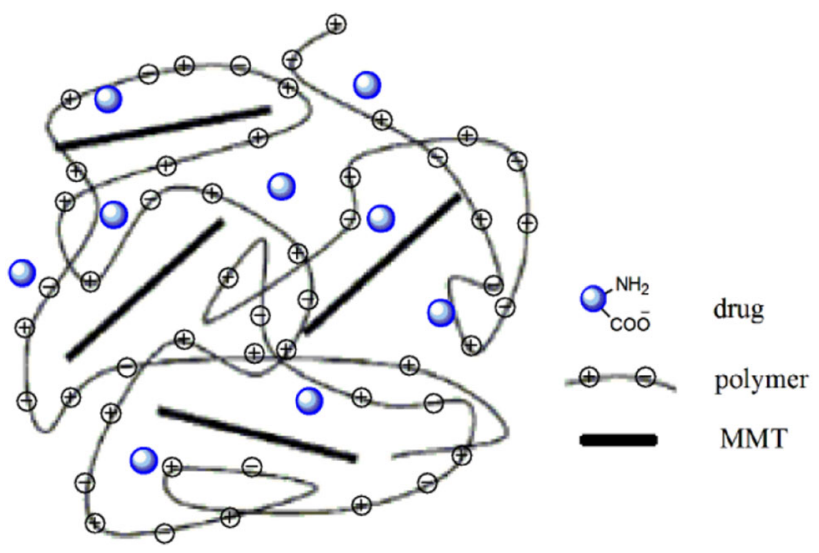

Figure 8. The schematic way of MTX loading in $\mathrm{pH}=7.4$.

(Figure 7b), and OMMT-PIL (Figure 7a), an increase in $\mathrm{C}$ is observed after polymerization.

\subsubsection{Thermal analysis}

The thermogravimetric analysis (TGA/DTG) profiles of MMT, OMMT, and nanocomposites are shown in Figure S1 (Supplementary Information). In the TGA profile of MMT (Figure S1A, Supplementary Information), all weight loss is due to evaporation of free water and water in the interlayer space and loss structural hydroxyl group. In the OMMT TGA profile (Figure S1B), the weight loss at $80-200^{\circ} \mathrm{C}$ is due to evaporation of free water and the weight loss at $200-500{ }^{\circ} \mathrm{C}$ is attributed to the organic substance. The structural water evolved in the region between $600-800^{\circ} \mathrm{C}$. The TGA profile of the OMMT-PIL and OMMT-CO(PIL-MAA) nanocomposites (Figure S1C and S1D, Supplementary Information) has three steps below $200^{\circ} \mathrm{C}, 200-450$, and up to $450^{\circ} \mathrm{C}$. Combustion of pending and polymer backbone took place at $200-450^{\circ} \mathrm{C}$. 

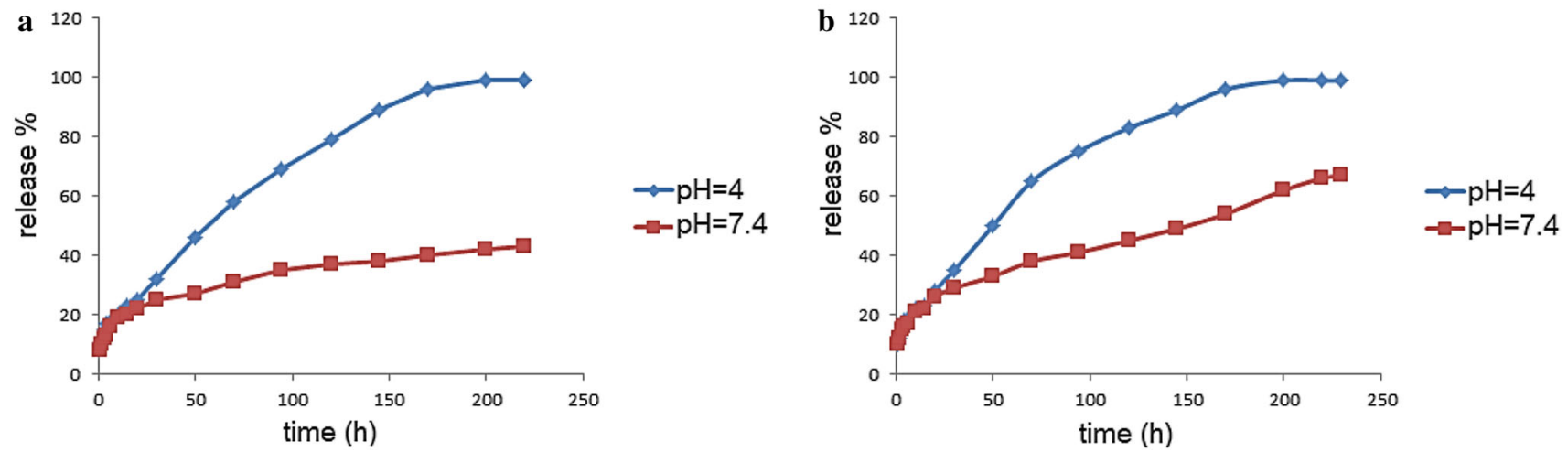

Figure 9. MTX release from (a) OMMT-PIL and (b) OMMT-CO(PIL-MAA) at $37^{\circ} \mathrm{C}$ in different $\mathrm{pH}=4$ and $\mathrm{pH}=7.4$.

\subsection{MTX loading}

Nanocomposites contain MMT nanoparticles and cationic polymers with the carboxylic acid group. On the other hand, MTX bears two amine and carboxylic groups in its structure and has a negative charge in $\mathrm{pH}=7.4 .{ }^{24}$ In this $\mathrm{pH}$ zeta-potential for OMMT-PIL is -1.1 (Figure S4, Supplementary Information), the negative charge of the nanocomposite is not large and thus loading of the drug can be done easily.

Incorporation of the drug in the nanocomposite was occurred by (a) intercalation in MMT layers by substitution with water molecules and interaction with a hydroxyl end group of MMT, (b) electrostatic interaction with cationic segments and carboxylic groups of the IL polymer and (c) anion exchange of the counter anion of the cationic polymer by drug molecules. The way of drug loading in this $\mathrm{pH}$ is shown in Figure 8. Efficient drug entrapment for OMMT-PIL and OMMT-CO(PILMAA) was $89 \%$ and $81 \%$, respectively, as estimated by formula 1. High concentration of the carboxyl group and positively charged moieties in OMMT-PIL cause the drug entrapment increase toward OMMT-CO(PILMAA).

3.2a In vitro MTX release study: Drug release studies of both nanocomposites were performed at $37^{\circ} \mathrm{C}$ for 10 days, in the simulated physiological environment of the intestine $(\mathrm{pH}=7.4)$ and the acidic environment of the cancer cells $(\mathrm{pH}=4)$. Figure 9 shows the release profile. As can be seen in the diagrams, for both nanocomposites, the release is $\mathrm{pH}$ dependent and it is more effective in acidic $\mathrm{pH}$. In this environment, the release has the highest percentage within ten days. Under these conditions, the carboxyl groups of medicines and nanocomposites and amine groups of the drug were protonated and thus, a repulsive force occurred between the drug molecules and the nanocomposites and this overcame to ionic interaction and hydrogen bonding, so the release of the drug happens easily. While in $\mathrm{pH}=7.4$, MTX has an overall negative charge and it is more attracted to the nanocomposites by hydrogen bonding and electrostatic interactions with the positive charge of the 1,2,3-triazole ring and shows a slower release. Comparing the percentage of drug release of the two nanocomposites in $\mathrm{pH}=4$ and $\mathrm{pH}=7.4$, the amount of release is 99 and 39\% for OMMT-PIL and 99 and $61 \%$ for OMMT-CO(PIL-MAA), respectively. This shows high $\mathrm{pH}$ dependence of OMMT-PIL.

\section{Conclusions}

New dual functional ILM based on 1,2,3-benzotriazolium was synthesized and intercalated into MMT using the ion exchange reaction. Then, the organicinorganic nanocomposites (OMMT-PIL) and OMMTCO(PIL-MAA) were prepared by incorporating positive charge and acidic groups in the framework. The anticancer drug (MTX) was successfully loaded on these nanocomposites and the in vitro release of it in $\mathrm{pH}=4$ and $\mathrm{pH}=7.4$ was investigated. The results showed that release from both the nanocomposites is completely $\mathrm{pH}$ dependent and is high in acidic $\mathrm{pH}$, while OMMT-PIL has high $\mathrm{pH}$ dependency. On the other hand, drug entrapment content in OMMT-PIL $(89 \%)$ is more than that of OMMT-CO(PIL-MAA) $(81 \%)$. It can be said that OMM-PIL can bring drug dosage down due to the high loading level and regular release of the drug. Also, having the antimicrobial compound benzotriazole in the nanocomposite structure produces a great potential to use as a substrate in the delivery of anticancer drugs in chemotherapy.

\section{Supplementary Information (SI)}

Some additional data about the characterization of monomers and nanocomposites (TGA thermograms and zeta-potential 
of nanocomposites, the original FT-IR and HNMR spectra of all synthesized molecules) are available in the supplementary information. Supplementary Information is available at www. ias.ac.in/chemsci.

\section{Acknowledgements}

This work is funded by the Azarbaijan Shahid Madani University.

\section{Compliance with ethical standards}

Conflict of interest. The authors report no declaration of interest. The authors alone are responsible for the content and writing of the paper.

\section{References}

1. Alvarez-Lorenzo C and Concheiro A 2014 Smart drug delivery systems: from fundamentals to the clinic Chem. Commun. 507743

2. Lee E-S, Kim J-H, Yun J-M, Lee K-S, Park G-Y, Lee B-J and Oh K-T 2010 Functional Polymers for Drug Delivery Systems in Nanomedicines J. Pharm. Investig. 4045

3. Schmaljohann D 2006 Thermo- and pH-responsive polymers in drug delivery Adv. Drug Deliv. Rev. 581655

4. Patel R, Pillay V, Choonara Y E and Govender T 2007 A Novel Cellulose-Based Hydrophilic Wafer Matrix for Rapid Bioactive Delivery J. Bioact. Comp. Polym. 22 119

5. Kevadiya B D, Pawar R R, Rajkumar S, Jog R, Baravalia Y K, Jivrajani H, Chotai N, Sheth N R and Bajaj H C 2013 pH-responsive MMT/acrylamide super composite hydrogel: Characterization, Anticancer drug reservoir and Controlled release property Biochem. Biophys. Rep. 143

6. Ghanbarzadeh S, Arami S, Pourmoazzen Z and Khorrami A 2014 Improvement of proliferative effect of Rapamycin on tumor cell lines by poly(monomethylitaconate)-based $\mathrm{pH}$-sensitive, plasma stable liposomes Colloids Surf. B Biointerfaces 115323

7. Sercombe L, Veerati T, Moheimani F, Wu S Y, Sood A K and Hua S 2015 Advances and Challenges of Liposome Assisted Drug Delivery Front. Pharmacol. 6286

8. Mahkam M, Latifpour A, Rafi A A, Gheshlaghi L M and Takfallah A 2015 Preparation of Montmorillonite-pHSensitive Positive Charges Nanocomposites as a Drug Delivery System Int. J. Polym. Mater. Polym. Bio. 6432

9. Cojocariu A, Porfire L, Cheaburu C and Vasile C 2012 Chitosan/montmorillonite composites as matrices for prolonged delivery of some novel nitric oxide donor compounds based on theophylline and Paracetamol Cell Chem. Technol. 4635

10. Li L, Takemura G, Li Y, Miyata S, Esaki M, Okada $\mathrm{H}$, Kanamori H, Khai N C, Maruyama R and Ogino A 2006 Preventive Effect of Erythropoietin on Cardiac
Dysfunction in Doxorubicin-Induced Cardiomyopathy Circulation 113535

11. Brannon-Peppas L and Blanchette J O 2012 Nanoparticle and targeted systems for cancer therapy Adv. Drug Deliv. Rev. 64206

12. Wilczewska A Z, Niemirowicz K, Markiewicz K H and Car H 2012 Nanoparticles as drug delivery systems Pharmacol Rep. 641020

13. Yeum J H 2011 Novel poly(vinyl alcohol)/Clay Nanocomposite Microspheres Via Suspension Polymerization and Saponification Polym. Plast. Technol. Eng. 50 1149

14. Joshi G V, Kevadiya B D, Patel H A, Bajaj H C and Jasra R V 2009 Montmorillonite as a drug delivery system: Intercalation and in vitro release of timolol maleate Int. J. Pharm. 37453

15. Iliescu R I, Andronescu E, Voicu G, Ficai A and Covaliu C I 2011 Hybrid materials based on montmorillonite and citostatic drugs: Preparation and characterization Appl. Clay Sci. $\mathbf{5 2} 62$

16. Cojocaru O A, Bica K, Gurau G, Narita A, McCrary P D, Shamshina J L, Barber P S and Rogers R D 2013 Prodrug ionic liquids: functionalizing neutral active pharmaceutical ingredients to take advantage of ionic liquid form Med. Chem. Commun. 4559

17. Uzagare M C, Sanghvi Y S and Salunkhe M M 2003 Application of 1-methoxyethyl-3-methyl imidazolium methanesulfonate in nucleoside chemistry Green Chem. 5370

18. Smith K, Bridson R and Leeke G 2011 Solubilities of pharmaceutical compounds in ionic liquids J. Chem. Eng. Data 562039

19. Resende J, Azevedo D E, Letourneau J-J, Espitalier F and Ré M I 2014 Solubility of a new cardioactive prototype drug in ionic liquids J. Chem. Eng. Data 59 1766

20. Hosseinzadeh F, Mahkam M and Galehassadi M 2012 Synthesis and characterization ionic liquid functionalized polymers for drug delivery of an anti-inflammatory drug Des. Monomers Polym. 15379

21. Leszczyńska A, Njuguna J, Pielichowski K and Banerjee J 2007 Polymer/montmorillonite nanocomposites with improved thermal properties: Part 1. Factors influencing thermal stability and mechanisms of thermal stability improvement Thermochim. Acta $\mathbf{4 5 3} 75$

22. Salehi R, Alizadeh E, Kafil H S, Hassanzadeh A M and Mahkam M 2015 pH-Controlled multiple-drug delivery by a novel an antibacterial nanocomposite for combination therapy RSC Adv. 5105678

23. Mahkam M, Abbaszad Rafi A and Mohammadzadeh Gheshlaghi L 2016 Preparation of novel pH-sensitive nanocomposites based on ionic-liquid modified montmorillonite for colon-specific drug delivery system Polym. Compos. 37182

24. Rasouli S, Davaran S, Rasouli F, Mahkam M and Salehi R 2014 Synthesis, characterization and $\mathrm{pH}-$ controllable methotrexate release from biocompatible polymer/silica nanocomposite for anticancer drug delivery Drug Deliv. 21155 